\title{
MARCOS HISTÓRICOS E TEÓRICOS DA ORGANIZAÇÃO DO CONHECIMENTO
}

\author{
MARCOS HISTÓRICOS Y TEÓRICOS DE LA \\ ORGANIZACIÓN DEL CONOCIMIENTO
}

Hagar Espanha Gomes *

\begin{abstract}
RESUMO
Introdução: O estudo reconhece um conjunto de demarcações históricas e teóricas em Organização do Conhecimento, que atravessam a Antiguidade, a Idade Média, a Modernidade e a contemporaneidade. Os elementos técnicos e os elementos teóricos são discutidos, da escrita à web semântica, como instâncias complemanteres no desenvolvimento das técnicas e das teorias de organização e representação do conhecimento. Objetivos: Abordar dois aspectos que consideramos relevantes no surgimento e desenvolvimento da Biblioteconomia/Ciência da Informação: as tecnologias e as reflexões que marcam abordagens teóricas. Metodologia: A proposta do estudo é uma revisão histórica, a partir de fontes bibliográficas, sobre a construção das ideias e dos artefatos em Organização do Conhecimento. Resultados: Cada produto de informação resultante trouxe, com o tempo, reflexão sobre os diversos fazeres. Dentre os marcos teóricos relevantes a destacar estão Kaiser com seu modelo de indexação, a Classificação Facetada de Ranganathan via Classification Research Group, a Teoria do Conceito de Dahlberg, que a complementa com princípios de definição, contribuindo para o desenvolvimento de taxonomias e ontologias. Conclusões: o estudo demonstra a relação objetiva entre as transformações técnicas e o desenvolvimento teórico da Organização do Conhecimento, permitindo identificar, contextualmente, os grandes marcos teóricos do domínio.
\end{abstract}

Palavras-chave: Organização do Conhecimento. História da Organização do Conhecimento. Tecnologias de organização e representação do conhecimento. Teoria em Organização do Conhecimento.

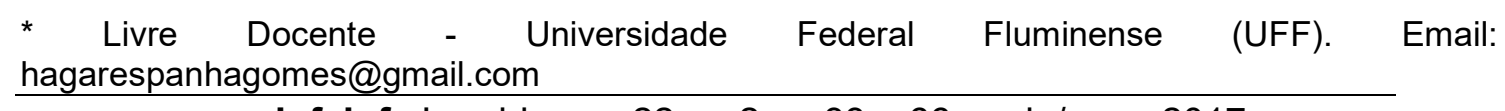

Inf. Inf., Londrina, v. 22, n. 2, p. 33 - 66, maio/ago., 2017.

http:www.uel.br/revistas/informacao/ 


\section{INTRODUÇÃO}

Nesta reflexão histórico-teórica pretendemos abordar dois aspectos que consideramos relevantes no surgimento e desenvolvimento da Biblioteconomia/Ciência da Informação: tecnologias que surgiram no tempo e as reflexões posteriores que marcam abordagens teóricas. Embora a narração deva privilegiar ocorrências no tempo, por vezes é preciso avançar, recuar, retomar o rumo, para juntar coisas que aparentemente são disjuntas.

A questão central é: a organização dos livros, inclusive a organização dos novos tipos de registro e serviços tem sido preocupação constante desde a Antiguidade. Os tempos mudam, mas a necessidade de organizar para facilitar o acesso e o uso da informação permanece. Mas não se trata do simples uso e acesso; trata-se de organizar o conhecimento disponível: memória e saber andam juntos. Podemos citar um autor o qual, apesar de expor a questão no início do século XX, o faz de maneira ainda atual nos dias de hoje:

Como fazer para que o público possa se informar rápida e seguramente dos recursos de toda espécie que oferece a enorme biblioteca acumulada pelos escritores de todos os tempos e de todos os países? Ou seja, o patrimônio literário e científico da Humanidade? Como ordenar este patrimônio de modo que todos os interessados desfrutem isso de modo tão completo e satisfatório quanto possível? Esse é o enunciado mais geral do problema bibliográfico. (LANGLOIS, apud MALCLĖS, 1956, p. 7)

Apesar de o autor se referir ao patrimônio literário e científico e ao problema bibliográfico ${ }^{1}$, podemos incluir os novos recursos de informação resultantes do avanço das tecnologias da informação, pois a busca de respostas é o que move as pesquisas atuais para atender a permanente e diversificada demanda de informação de qualquer natureza: científica, técnica, empresarial e por aí vai.

1 Não podemos nos esquecer que a atividade bibliográfica teve início como atividade de eruditos.

Inf. Inf., Londrina, v. 22, n. 2, p. 33 - 66, maio/ago., 2017. 
Deve ficar claro, no entanto, que organização, nas atividades de informação, significa classificação em seu sentido mais amplo, incluindo indexação (atribuição de uma classe de assunto ou aspecto a um documento/recurso), esquemas de classificação com ou sem notação, terminologia, tesauros, taxonomias e assemelhados.

Alguns marcos têm repercussão mais ou menos indireta no surgimento de produtos e técnicas e nas bases teóricas decorrentes da necessidade de organização da informação e do conhecimento.

Vamos considerar primeiramente o período anterior à atividade profissional dedicada à organização da informação que inclui iniciativas desde tempos antigos até a primeira metade do século XIX. Para entender aquelas contribuições é preciso conhecer as circunstâncias, as iniciativas e necessidades de informação que levaram às primeiras organizações da informação, nomeadas de forma diversa, ora bibliografia, ora catálogo, ora índice, não importando o que se organizava: os próprios livros ou seu conteúdo ou outros artefatos. As mudanças são poucas, se pensarmos no lapso de tempo. Com a profissionalização e o desenvolvimento tecnológico a partir da segunda metade do século XIX as mudanças ocorrem provavelmente em 'progressão geométrica' se nos dispuséssemos a tal avaliação. As contribuições teóricas seguem na mesma 'velocidade'.

\section{MARCOS HISTÓRICOS}

Podemos começar com a invenção da escrita. Os catalogadores ou 'ordenadores do universo' - assim chamados pelos sumérios - deixaram um vestígio do catálogo de uma 'Casa dos Livros' descoberto nas escavações em Edfu no Egito, datando aproximadamente de 2000 a.C., o qual por sua vez, 'começa com uma lista de vários outros catálogos: $O$ livro do que se encontra no templo, O livro dos domínios, A lista de todos os escritos gravados em madeira, O livro das estações do Sol e da Lua, O livro dos lugares e o que há neles e assim por diante'. (MANGUEL, 1997, p. 219-220) 
Um dos primeiros estudiosos da Classificação bibliográfica (RICHARDSON, 1912) registra, ainda, que bibliotecas de templos egípcios e hebreus tinham alguma forma de organização de seus livros; bibliotecas assírias e babilônicas tinham catálogos classificados.

O médico Galeno, na segunda metade do Século II d.C. tem sido considerado como um dos primeiros organizadores de sua própria produção em De libris propris, ordenada em diversos aspectos como: Fisiologia e Anatomia, Higiene, Etiologia, Semiótica, Farmácia, Instrumentos da prática clínica, Terapêutica.

Para Richardson (1912), no entanto, a organização dos livros começa com Calímaco (século III a. C). Seu catálogo - Pinakes ${ }^{2}$ - foi por ele mesmo indicado como 'lista', e nela as obras existentes na Biblioteca de Alexandria estavam organizadas por grandes temas ou gêneros. Ele talvez seja o pai da classificação de livros bem como dos sistemas teóricos, pois teria orientado os reis do Egito na formação de uma biblioteca (RICHARDSON, 1912). Calímaco dividiu a biblioteca em estantes ou mesas (pinakoi) organizadas em oito classes ou assuntos: teatro, oratória, poesia lírica, legislação, medicina, história, filosofia e miscelânea. (MANGUEL, 1997). A Calímaco devemos também um expediente de catalogação que se tornaria lugar comum: o costume de arranjar os volumes em ordem alfabética embora algumas inscrições gregas de cerca do século II a.C também registrem esse tipo de ordenação. Ainda segundo Manguel, 'a biblioteca de Alexandria e seus catálogos tornaram-se os modelos, primeiro das bibliotecas da Roma imperial, depois das do Oriente bizantino e, mais tarde, da Europa cristã.' (MANGUEL, 1997)

$\mathrm{Na}$ Idade Média, como é natural, as bibliotecas encontravam-se nos mosteiros e nos centros de filosofia e ciências do mundo islâmico. A criação de universidades nos séculos XI e XII - período conhecido como Renascimento do

\footnotetext{
2 Este catálogo desapareceu e dele se tem conhecimento por citações posteriores.
}

Inf. Inf., Londrina, v. 22, n. 2, p. 33 - 66, maio/ago., 2017. http:www.uel.br/revistas/informacao/ 
século XII - inicia um processo de mudança na sociedade ocidental: nobres letrados são os que podem arcar com o alto custo de um manuscrito para organizar e manter, assim, suas bibliotecas pessoais segundo esquemas particulares de classificação. No entanto, o período se caracteriza pela grande presença de repertórios bibliográficos, elaborados por e para homens de saber. 3

No que tange a catálogos, dentre os muitos exemplos registrados por Manguel (1997), ressaltam-se aqui os que propõem algum modelo de organização. Hugo de São Vítor propõe, em 1120, um sistema no qual o conteúdo de cada livro é brevemente resumido e distribuído em uma das três categorias correspondentes à divisão tripartite das artes liberais: teórica, prática e mecânica. Em 1250, Richard de Fournival imagina um sistema baseado em um modelo horticultural: como um jardim, em que as pessoas poderiam 'colher os frutos do conhecimento' em três canteiros, correspondendo à filosofia, às ciências lucrativas e à teologia, cada um deles com um sumário ou tabula do assunto do canteiro (areola). Criou ele um método de notação para organizar os livros nas mesas.

O jardim de De Fournival tinha por modelo, pelo menos em parte, as sete artes liberais em que se dividia o sistema tradicional de educação medieval: gramática, retórica, lógica, aritmética, geometria, astronomia e música. Estabelecidos no início do século $\mathrm{V}$ por Marciano Capela, acreditava-se que aqueles sete temas encarnavam todo o campo da sabedoria humana, à parte a medicina, o direito e a teologia (MANGUEL 1997, p. 223).

Este modelo de organização se tornou bastante popular e influenciou iniciativas posteriores. Mas não de forma absoluta.

Enquanto a Idade Média se fechava no mundo cristão, os muçulmanos traduziam os gregos e assim desenvolveram uma civilização avançada em

\footnotetext{
${ }^{3}$ Sugere-se a consulta ao pequeno livro de Mme. Malclès, La Bibliographie, bastante informativo a respeito. Mas sua obra mais geral, monumental, Les Sources du travail bibliographique, representa, talvez, a maior quantidade de informação a respeito.
}

Inf. Inf., Londrina, v. 22, n. 2, p. 33 - 66, maio/ago., 2017. 
especial nos campos da matemática, da astronomia, da biologia e da medicina. O mundo cristão quis acesso a tais textos um tanto esquecidos do mundo ocidental. A solução foi traduzir essas traduções para o latim - já um tanto decadente $-\mathrm{e}$ isso "obrigou os estudiosos a reconsiderar a divisão que De Fournival achara tão natural" ao tomarem conhecimento do pensamento de Aristóteles. (MANGUEL, 1997, p. 224).

\subsection{A Imprensa}

A Imprensa é um marco divisório na organização do conhecimento. Para Mme. Malclès (1956) o século XVI é considerado como Epoque Savante. O período marca o domínio das Ciências Humanas. A introdução dos tipos móveis de metal por Gutenberg é responsável por uma grande mudança neste panorama; de fato, fez toda a diferença. Produzidos em série, posteriormente impressos em papel, o produto naturalmente seria mais barato. Casas editoras iniciam a publicação em escala de obras da Antiguidade clássica; a produção bibliográfica leva ao surgimento mais amplo de bibliotecas particulares, de bibliografias nacionais, gerais e especializadas, aumenta o debate de idéias com a divulgação dos textos, e a atividade bibliográfica aos poucos se profissionaliza. Os livros impressos colocam facilmente na mão das pessoas a possibilidade de suas comparações. Bibliotecas e bibliografias são inúmeras e são 'testemunhas do estado de avanço de cada ciência'. (MALCLĖS, 1956).

\subsection{Surgimento da Bibliografia moderna}

Uma publicação marcante, já na primeira metade do século XVI, é a Bibliotheca Universalis (1545), de Konrad Gesner. Gesner ${ }^{4}$ foi um erudito, um homem do Renascimento: lingüista, naturalista, pesquisador, publicador de

\footnotetext{
${ }^{4}$ As informações são extraídas principalmente do artigo de Nelles (cf Referências ao final)
}

Inf. Inf., Londrina, v. 22, n. 2, p. 33 - 66, maio/ago., 2017. 
obras científicas, conhecedor de línguas já consideradas 'mortas'. Destaca-se, no que nos diz respeito, por sua monumental Bibliotheca Universalis. Em visita às bibliotecas das cidades por onde teve oportunidade de passar - na Suíça, Alemanha, Áustria, França - compulsou de primeira mão as obras arroladas. Alguns autores estimam 15000 títulos de 3000 autores (MALCLÈS, 1956), outros, 25000 títulos e 1000 autores (NELLES, 2009). De qualquer modo, os números são surpreendentes. Sua bibliografia, no entanto, se caracteriza de um lado, pelo valor dado aos livros compulsados e, de outro, pelo índice ou Pandectas.

A Bibliotheca é uma bibliografia crítica, ou seja, seu organizador emite comentários a respeito de várias obras e inclui, por vezes, dados sobre os autores. Releva no repertório o valor dado a certos títulos para os quais fornece abundante informação extraída dos sumários ou das introduções incluindo por vezes até mesmo excertos. Por exemplo, para Aristóteles, Gesner dedica 40 páginas com comentários críticos, organizando os títulos segundo um arranjo sistemático; para Santo Agostinho dedica mais de 24 páginas; edições anteriores de uma ou outra obra são também alvo de comentários. Mas inclui também autores menos conhecidos à época, pois caberia ao leitor julgar sua importância posteriormente.

Gesner deve ter percebido que apenas a organização por autor - um tanto comum no período - restringiria o acesso apenas àqueles que já tivessem conhecimento de uma dada obra, ou seja, não seria uma fonte de informação, mas de identificação. Em uma publicação posterior ${ }^{5}$ as mesmas obras estão distribuídas em vinte tópicos, o que representou uma mudança na organização da informação em seu tempo. Sistemas de classificação para repertórios bibliográficos serão então adotados aqui e ali, influenciando gerações posteriores, inclusive responsáveis por organização de bibliotecas.

${ }^{5}$ Gesner, Konrad - Pandectarum .1548

Inf. Inf., Londrina, v. 22, n. 2, p. 33 - 66, maio/ago., 2017. http:www.uel.br/revistas/informacao/ 
Pandectarum é um índice sistemático da Bibliotheca, com subdivisões. Seu esquema reflete, de modo amplo, a cultura pedagógica e as hierarquias intelectuais da Baixa Idade Média, amenizadas pela nova situação privilegiada dada aos mundos naturais e humanos no Renascimento Ao incluir novas áreas avança no trivium e quadrivium (NELLES, 2009).

O valor de suas contribuições na construção e organização da Bibliotheca confere o epíteto de 'Pai da Bibliografia'. Mas não apenas por isso, mas por sua preocupação com o livro, com o conhecimento em si. É isso que ele busca, pois, ordenar o conhecimento requer organizar antes o mundo do próprio livro. Os princípios que ele adotou vão influenciar bibliógrafos, posteriormente, devido ao tratamento dado a obras de grandes e prolíficos autores: suas edições, comparações e comentários críticos. Os vários tipos de bibliografia atualmente - não importam as classificações - crítica, analítica, descritiva, textual - encontram, de alguma forma, subsídios em Gesner.

\subsection{Surgimento da bibliografia corrente}

Como uma mercadoria, o livro impresso encontrou espaço nas Feiras tradicionais de Leipzig e Frankfurt, surgindo ali a Feira do Livro. A primeira, especialmente, incluiu a produção bibliográfica já em 1632 e perdurou até o final da II Guerra Mundial. A de Frankfurt teve curta duração. Uma nova Feira foi criada na então Alemanha Ocidental. Para o que nos interessa, a de Leipzig tem importância fundamental: surge ali a bibliografia nacional corrente, como uma atividade econômica e não como iniciativa de eruditos; ali se firmam os elementos da descrição bibliográfica e da organização alfabética de assunto. Esta produz outros desdobramentos e muita discussão no ambiente bibliotecário britânico e norte-americano ainda nos tempos atuais.

A nova atividade bibliográfica deu surgimento à 'bibliografia profissional', embora a bibliografia retrospectiva, elaborada por eruditos, ainda se mantivesse. A descrição bibliográfica de interesse comercial torna-se mais 
simples, pois um padrão para o livro impresso começa a se firmar: página-derosto, sumários, paginação e assemelhados.

O século XVII registra contribuições importantes na organização de bibliotecas. Dentre os filósofos, Francis Bacon foi o que mais fortemente influenciou a construção de esquemas bibliográficos e bibliotecários baseados em disciplinas. Embora bibliotecas particulares e religiosas tivessem provavelmente instrumentos e normas para organização de suas coleções, dois estudiosos e responsáveis por organização de bibliotecas são relevantes neste século: Gabriel Naudé (1600-1653) e o cientista e filósofo Gottfried Wilhelm Leibniz (1646-1716); deles temos conhecimento pela divulgação de suas ações e princípios adotados. Não importa tanto o sistema de classificação seguido por eles, mas sim sua percepção da classificação do conhecimento quando aplicada à organização de livros.

Naudé foi um erudito francês que atuou como bibliotecário de eminentes personalidades da época e ficou conhecido pela publicação de um manual de organização de bibliotecas - Advis pour dresser une bibliothèque - publicado em 1627, com algumas reedições, uma delas mais de duzentos anos depois; atualmente está disponível na Internet ${ }^{6}$, o que denota o interesse por sua contribuição para o estudo da área. Trata-se de um dos relatos mais antigos sobre classificação para bibliotecas - entre outros temas - apoiada em disciplinas, abordando igualmente de maneira bastante abrangente os principais aspectos para a formação de acervo, a organização, o uso; ele aborda até mesmo aspectos ligados à instalação física de uma biblioteca. No capítulo 7, "A ordem que convém dar [aos livros]", a classificação, segundo ele, é necessária para permitir encontrar facilmente o que se deseja. Sem isso, não merece o nome de biblioteca, do mesmo modo como não se dá

${ }^{6}$ http://www.enssib.fr/bibliotheque-numerique/documents/48749-advis-pour-dresser-unebibliotheque-par-gabriel-naude.pdf

Inf. Inf., Londrina, v. 22, n. 2, p. 33 - 66, maio/ago., 2017. http:www.uel.br/revistas/informacao/ 
[...] a um punhado de trinta mil homens o nome de exército se não estiverem dispostos em esquadrões sob a direção de chefes e capitães, ou [a] uma grande quantidade de pedras e materiais o nome de palácio ou casa, se não estiverem colocados segundo o que deles se requer para fazer disso uma construção perfeita e acabada. (NAUDÉ, 1627, p. 97-98)

Na mesma época, podemos registrar a atuação do filósofo Leibniz que trabalhou mais de uma vez como bibliotecário em algumas cortes. Filósofo e matemático, Leibniz formou-se em Direito, mas não quis seguir a carreira acadêmica. Trabalhou como bibliotecário para vários nobres e organizou catálogos ordenados sistematicamente, adotando em alguns casos esquemas já desenvolvidos por outros, como Gesner, Draud e Naudé, seu contemporâneo. Fez um exaustivo estudo das iniciativas de classificação em bibliotecas. Embora conhecendo contribuição anterior, Leibniz "parece ter desenvolvido seu esquema de modo independente" (SCHULTE-ALBERT, 1971 , p. 149) ${ }^{7}$.

Numa carta a Pedro, o Grande, da Rússia, ele expõe sua abordagem relativa à classificação das ciências, apresentada mais como um plano de estudos para jovens. Como bibliotecário, concordava com Naudé que a divisão de acordo com as faculdades da universidade e as profissões representavam o sistema de classificação bibliotecária de modo mais fácil, menos complicado e mais natural e utilizou esta base para seus próprios esquemas (SCHULTEALBERT, 1971).

Mesmo sendo filósofo, rejeitava uma classificação rigorosamente lógica quando aplicada a bibliotecas. Bastante familiarizado com próprias da organização do conhecimento/das ciências, ao se defrontar com as peculiaridades da organização/classificação dos livros, percebeu as limitações da linearidade que o obrigava a colocar um livro após o outro nas estantes, embora o conhecimento nele registrado tivesse múltiplas relações com outros

${ }^{7}$ As informações a respeito de Leibniz são extraídas do estudo de Schulte-Albert. Cf referência ao final.

Inf. Inf., Londrina, v. 22, n. 2, p. 33 - 66, maio/ago., 2017. 
livros, além daquele aspecto selecionado para ordená-lo fisicamente, não importando quão importante pudesse ser (SCHULTE-ALBERT, 1971)

Em toda sua classificação, esteve bastante atento aos princípios da garantia literária. Assim, embora não acreditasse em Astrologia, Artes da adivinhação, e outras 'pseudo-ciências' cuja literatura já era abundante, incluiu tais tópicos em seu esquema para 'dar-Ihes um lugar na estante'. Leibniz viu, ainda, que, para suprir as limitações de um catálogo sistemático, um índice alfabético de assunto complementaria o esquema sistemático, inovando-o com a inclusão de elementos sindéticos. Sua experiência mostrou que um índice de autor complementaria o catálogo facilitando a consulta por este aspecto. Então, Leibniz deixou igualmente sua marca na Organização do Conhecimento. $O$ próximo marco histórico é a Revolução Francesa.

A Revolução Francesa trouxe o surgimento de grandes bibliotecas municipais, resultantes dos confiscos das bibliotecas monásticas e da nobreza. Eram coleções eruditas, de pouco interesse para o leitor comum. De fato, eram 'públicas', do poder público, mas ainda de uso restrito: as coleções, devido a suas origens, não eram adequadas ao grande público.

Tais bibliotecas eram dirigidas por homens de saber. Apesar de 'abertas' para o público, o leitor tinha acesso ao acervo apenas via catálogos os quais, impressos periodicamente, eram classificados (catálogos metódicos, ou sistemáticos). Este ambiente não proporcionou mudanças na atividade bibliotecária naquele país. Apesar da grande ênfase na Educação como uma bandeira da Revolução Francesa visando estender o acesso ao conhecimento de maneira bastante abrangente para todo e qualquer cidadão (COMPAYRÉ, 2012), os dirigentes eram pessoas de grande saber, conservadoras, talvez, restringindo o acesso apenas aos catálogos; de fato, o catálogo representava a biblioteca (LÉTOUBLON; SGARD, 2014). Publicados anualmente, os catálogos passaram a adotar na França 'o sistema dos livreiros', de Brunet.

Voltando à organização alfabética, um dos desafios dos catálogos das bibliotecas e, mesmo, da bibliografia corrente, era a dificuldade de organizar os registros de forma sistemática - como prever assuntos que poderiam ser 
incluídos no acervo ainda em construção? - em oposição às bibliografias que eram retrospectivas, voltadas a uma área de assunto que poderia ser sistematizada. A ordem alfabética vinha ganhando terreno, para o bem ou para o mal. Se na França as bibliotecas publicavam periodicamente seus catálogos sistemáticos - porque impressos, e, portanto, retrospectivos -, no Reino Unido o catálogo do British Museum era corrente, organizado segundo o modelo alfabético-por-classes, ou seja, os termos da lista indicariam classes, e a subdivisão as sub-classes. Por exemplo, Animais - Cavalos; Animais - Gatos. O acesso ao tópico não era direto, mas através de um termo mais amplo. Era, talvez, uma forma um pouco sofisticada para o público leigo e que será contestada pelos bibliotecários norte-americanos.

A ruptura da organização sistemática e a adoção do arranjo alfabético é uma das conseqüências da profissionalização, já iniciada, de alguma forma, com os catálogos das Feiras de Livros. Nestas, a divulgação dos livros se dava por listas de autor e de assunto conforme as palavras representativas do título, e não mais por tópicos que reuniriam conjuntos de títulos como nos repertórios retrospectivos, sistemáticos. A ordenação alfabética se populariza. Esta prática parece ter permanecido até o século $\mathrm{XX}$, também nos catálogos de bibliotecas, quando ainda se defendia a palavra significativa do título como base para a indexação (METCALF, 1959)

De fato, ocorre então uma discussão naquele momento, sobre o que se entendia por 'catálogo'. Se significava lista alfabética de autores - "havia dúvidas se as entradas de assunto ainda seriam um catálogo no sentido estrito" - e se os cabeçalhos que eram independentes dos títulos dos livros poderiam ser considerados um catálogo classificado (METCALF, 1959 p. 29-30). Talvez por isso mesmo o catálogo de assunto da Biblioteca do British Museum (1881) tenha se chamado British Museum Library Subject Index: nele os assuntos eram organizados em ordem alfabética segundo classes e não por um tópico específico, no nível do livro indexado.

A discussão permanece. Um estudo desenvolvido em 1955 no Royal College of Physicians, Edinburgh, revelava que ainda não existia uma distinção 
rígida entre catalogação de assunto e indexação: os termos eram usados como sinônimos. No Relatório produzido, uma lista de livros por diversos autores seria um catálogo, mas a lista de referência de assuntos tratados em um livro seria um índice (TAUBER, 1957). De fato, a diferença entre ambos é adjetiva, pois requerem alguns princípios comuns em sua elaboração como padronização do vocabulário, controle de sinônimos e presença de referências cruzadas. Mas isso já seria uma discussão teórica, ausente ainda hoje (será?). Podemos dar uma olhada nos programas das Escolas e verificar se isso se discute.

Ainda a Revolução Francesa: É lugar comum afirmar que os ideais da Revolução Francesa tiveram consequências nos Estados Unidos. No que se refere à Educação, ali eles se concretizaram não apenas nas instituições de ensino em todos os níveis, mas de modo muito especial nas bibliotecas gerais e acadêmicas, igualmente consideradas como 'templos do saber'. Com acervos de obras recentes, os livros podiam ser consultados, manuseados, emprestados e, em caso de perda, substituídos. O livre acesso às estantes foi estabelecido. Tem início, então, um período de transição para atividades de informação realizadas por profissionais e não mais por eruditos. Os resultados de tais iniciativas foram principalmente: o desenvolvimento de esquemas de classificação, a criação dos catálogos alfabéticos, a criação do serviço de referência, e os primeiros cursos de biblioteconomia. A segunda metade do século XIX dá início à atividade profissional em bibliotecas e o desenvolvimento de esquemas de classificação bibliotecária foi afetado, de algum modo, pelas propostas de classificação do conhecimento de diversos filósofos e pensadores em geral.

A Revolução é, então, um marco histórico quando se volta o olhar para o desenvolvimento bibliotecário nos Estados Unidos e sua contribuição para a biblioteconomia no mundo ocidental principalmente. 


\subsection{A Segunda Revolução Industrial}

O final do século XIX é um período talvez dos mais ricos na produção de tecnologia de comunicação e registro do conhecimento. Podemos citar, em especial, fotografia (1826), telefone (1876), filme fotográfico (I879), telégrafo sem fio (1890), rádio (1890), cinematógrafo (1895).

A Segunda Revolução Industrial - nosso próximo marco histórico - leva ao desenvolvimento de atividades especializadas de informação técnicocientífica, não acadêmica, não universal (para usar a linguagem da época). Manuais de procedimentos dos equipamentos industriais, boletins relativos a atividades comerciais e industriais, enfim, toda uma literatura técnica é produzida em decorrência de novos produtos e serviços. Serviços especializados se tornam uma necessidade nas organizações comerciais, nos laboratórios de pesquisa, dentre outros (SHERA; EGAN 1961), e nestes ambientes privilegia-se o conteúdo dos documentos em detrimento de sua organização física: nasce aí a indexação. A tentativa de sistematizar tal atividade, levou Kaiser a publicar Systematic indexing (1911), talvez a primeira obra em que se procura estabelecer princípios e critérios.

Por outro lado, iniciativas como as de Otlet, embora voltadas para a elaboração de repertórios bibliográficos, são também um reflexo desses desenvolvimentos tecnológicos. Ao considerar a necessidade de repertoriar documentos não-livro como por exemplo filmes, fotografias, registros sonoros, ele provoca o surgimento de um novo campo de atuação profissional para a qual ele cunha a palavra Documentação: os repertórios privilegiam a organização sistemática. Com padrões de registro e técnicas de reprodução seria possível formar uma grande Rede universal de informação e de acesso ${ }^{8}$.

O período que vai aproximadamente da segunda metade do século XIX à primeira metade do século $\mathrm{XX}$ marca o início da atividade profissional

8 O microfilme, visto como meio de cópia de documentos, teve a participação de Otlet no seu aprimoramento para aquela finalidade.

Inf. Inf., Londrina, v. 22, n. 2, p. 33 - 66, maio/ago., 2017. 
também nos serviços de informação/documentação (especializados). No século XX, após a Segunda Guerra Mundial (ou em seu bojo), os avanços tecnológicos do século anterior resultam nas primeiras máquinas de processamento de dados que vão levar aos computadores.

Dois movimentos marcam, então, este período, resultantes, de um lado, do impacto da Revolução Francesa -: o desenvolvimento de bibliotecas públicas e acadêmicas - e seus sistemas de classificação bibliotecária, e o impacto da Segunda Revolução industrial, com o surgimento de serviços especializados. Vale a leitura do artigo de Shera e Egan (1961) como Introdução ao livro de Bradford.

O desenvolvimento de produtos e técnicas para a organização dos livros e de seu conteúdo resultaram em:

- surgimento de esquemas de classificação para a organização física dos documentos (esquemas de Cutter, Brown, Dewey e tantos outros);

- surgimento de um esquema para a organização da informação em repertórios bibliográficos (Classificação Decimal Universal)

- surgimento dos 'sistemas de indexação' em serviços de informação/ documentação nas organizações privilegiando igualmente a organização da informação em ambiente especializado;

- surgimento de catálogos alfabéticos de assunto de entrada direta.

\subsection{Marcos históricos na segunda metade do Século XX}

Mecanização nos serviços de informação, Recuperação de informação, surgimento da Ciência da Informação - esses são os marcos do período.

As mudanças científicas, tecnológicas e tantas outras, repercutiram então nos registros do conhecimento (produtos) e serviços potencializados, inicialmente, com a introdução da computação no final da primeira metade do século $X X$ e, posteriormente, com o surgimento da Internet na segunda metade. 
A questão da recuperação da informação, no entanto, embora ainda sem ser assim nomeada, teria sua origem no século anterior, com os sistemas de indexação no tratamento dado à informação técnica, comercial e científica. Vai ser assim nomeada apenas nos anos 50 do século seguinte com a introdução de dispositivos mecânicos e semi-mecânicos para indexação/recuperação.

Nos Estados Unidos a atividade de informação já havia merecido interesse do Estado. Em 1851 num Relatório destinado ao Senado, o Smithsonian Institute estimava que 'cerca de 20000 volumes (incluindo folhetos) são publicados anualmente e a menos que esta quantidade de publicações seja adequadamente organizada, elas serão esmagadas por sua própria carga pesada' (JOSEPH, 1851 apud KENT, 1971, p. 6). E o relatório segue defendendo a indexação dos assuntos não apenas de livros, mas de atas, trabalhos de congresso. No entanto, o assunto foi ignorado pelo Senado.

O reconhecimento da crise veio não apenas nos periódicos científicos que tradicionalmente ofereciam os meios de registros de publicação dos resultados de pesquisa (KENT, 1971. p. 7), mas na documentação técnica produzida pelos laboratórios de pesquisa e desenvolvimento. O resultado foi uma nova avalanche de conhecimento tão grande que os métodos existentes de coleta e organização dos registros já não podiam ser considerados eficazes.

No Reino Unido, no início do século $X X$, a necessidade de apoiar a pesquisa científica e tecnológica para enfrentar a competição com Alemanha e Estados Unidos, provocou igualmente esforço de pessoal envolvido com a organização de documentos técnicos e científicos produzidos pelos laboratórios de pesquisa (MUDDIMAN, 2005). Após o término da II Guerra Mundial a situação ficou mais crítica. Organizações especializadas foram criadas e o envolvimento de cientistas de alta envergadura resultou na organização da International Conference on Scientific Information realizada em 1948, em Londres. A avalanche de novos conhecimentos científicos e tecnológicos produzida pelo esforço de guerra trouxe para os pesquisadores a necessidade de discutir o modelo de produção da comunicação científica, o modelo de distribuição, os serviços de registro e recuperação desta documentação, como 
se depreende do temário daquela Conferência: 1) publicação e distribuição de trabalhos originais; 2) serviços de resumos; 3) indexação e outros serviços bibliotecários; 4) artigos de revisão e relatórios anuais. A Seção 3 incluiu discussões sobre CDU, indexação alfabética, processos fotográficos, métodos de seleção mecânica, treinamento de bibliotecários especializados e especialistas em informação, serviços de tradução e problemas com obtenção de cópias da literatura científica para cientistas distantes das instituições de pesquisa.

Várias iniciativas relevantes tiveram origem a partir daquele evento. Uma ação imediata foi a criação de um comitê científico sob a coordenação do físico J. D. Bernal, para estudar a natureza da classificação e de sistemas de classificação bibliográfica existentes, que deu origem, entre outros, ao Classification Research Group (CRG) do Reino Unido. (MUDDIMAN, 2005; SPITERI, 1995; BROUGHTON. 2011).

A atuação de órgãos como a ASLIB, criada em 1924 como meio de apoiar o esforço de pesquisa para enfrentar a competitividade no campo da Ciência e da Tecnologia, a Conferência de 1948 e, na continuação e como decorrência, a criação do CRG, são elementos que, certamente, marcam a consolidação da atividade chamada 'informação científica'. É interessante observar que os russos propõem nomear Informática essa nova área, mas uma empresa com esse nome teria impedido os norte-americanos de usá-lo9.

Para Aldo Barreto (2002; 2008), a Conferência marca o nascimento da Ciência da Informação, ainda nomeada informação científica ${ }^{10}$, o que pode ser aceito, uma vez que o quadro temático discutido naquela Conferência será objeto, ainda que não explicitamente, de desenvolvimentos teóricos e tecnológicos posteriores. É nos Estados Unidos que esta área de conhecimento passa a se chamar Ciência da Informação nos anos 60 .

\footnotetext{
${ }^{9}$ Ainda não encontramos registro a respeito.

$10 \mathrm{Na}$ antiga União Soviética o primeiro livro a abordar teorias e técnicas automáticas de tratamento da informação também empregou a expressão 'informação científica', cuja teoria veio a se chamar Informatik.
}

Inf. Inf., Londrina, v. 22, n. 2, p. 33 - 66, maio/ago., 2017. 
Este período marca a introdução do conceito de Recuperação de Informação - expressão cunhada por Calvin Mooers em 1950 - já associada aos novos meios de tratamento da informação empregando ferramentas como fichas perfuradas na margem e máquinas seletoras, conforme se observa numa grande quantidade de depoimentos registrados durante um Simpósio internacional sobre Sistemas de Recuperação de Informação realizado por iniciativa da Escola de Biblioteconomia da então Western Reserve University e de seu Center for Documentation and Communication Research. ${ }^{11}$ Naquele momento privilegiavam-se esquemas codificados para estruturar e representar conteúdos dadas as limitações das tecnologias disponíveis. Aquele conceito é fruto da grande quantidade de documentação científica e técnica gerada a partir do esforço de Guerra no início do Século XX. Mooers introduz ainda o conceito de descriptor para o vocabulário de recuperação representado por códigos numéricos. Limitados em número pela potencialidade dos sistemas de fichas perfuradas nas margens, nem sempre era possível alcançar a especificidade desejada; assim, cada descriptor ${ }^{12}$ abrangia um certo número de temas.

Mais adiante, com a possibilidade de acesso aos sistemas computadorizados a partir de palavras e não mais códigos e a introdução da álgebra booleana para recuperar informação em bases de dados, o controle de vocabulário se torna crucial. Os cabeçalhos de assunto perdem a parada. $O$ instrumento de controle é o tesauro, ainda com palavras únicas.

A profissionalização da área leva ao aparecimento de associações especializadas na área da documentação, ressaltando-se: ASLIB (1924), UFOD (1931), Association of Research Libraries (1932), ADI (1937 - depois ASIS), bem como um organismo internacional, a Federação Internacional de

11 O termo 'documentação' ainda presente nas instituições norte-americanas caiu em desuso, em favor de 'ciência da informação'.

$12 \mathrm{O}$ termo 'descritor', em português é empregado sem um sentido preciso.

Inf. Inf., Londrina, v. 22, n. 2, p. 33 - 66, maio/ago., 2017. 
Documentação (1937), continuação do Instituto Internacional de Bibliografia (1895), o que prova a pujança da área.

\subsection{O saber da Biblioteconomia: abalado com a Ciência da Informação?}

Os instrumentos de tratamento de informação empregados nas bibliotecas públicas e acadêmicas - ou seja, as tabelas de classificação e os cabeçalhos de assunto - não atendiam 0 interesse específico dos pesquisadores por serem gerais e voltados para o tratamento de obras monográficas e livros, enquanto a documentação era caracteristicamente de não-livros (relatórios, patentes, artigos...) presente nas bibliotecas especializadas de empresas e seus serviços de documentação/informação (information bureaux) e nos laboratórios de pesquisa.

Ainda assim, eram considerados fundamentais os instrumentos empregados na biblioteca tradicional, fossem eles dispositivos independentes ou empregados em conjunto com máquinas de busca. 'Classificação, catalogação e indexação, a despeito das viradas que possam ocorrer na literatura da área, têm a ver com todos aqueles interessados na 'recuperação da informação' ou o que os bibliotecários têm chamado de análise de assunto'. (TAUBER, 1957, p. 39). Tauber reconhece, então, que os bibliotecários já haviam percebido que a classificação na biblioteca era monodimensional e que procuravam contornar esta limitação através dos cabeçalhos de assunto para prover abordagem múltipla.

Embora a CDU e a Colon Classification já permitissem esta forma de abordagem, eram aparentemente desconhecidas nos Estados Unidos. Mas havia a necessidade de desenvolver métodos e técnicas específicos para a nova realidade. Isto não significava, porém, que os bibliotecários não devessem atuar naquela área: 'Como bibliotecários temos que descobrir que nosso ofício é bibliografia e assumir a responsabilidade disso. Nesta disciplina devemos empregar não apenas nosso talento, mas todos os talentos, invenções e conhecimento técnico dó período. Ou então, o trabalho de 
bibliografia vai para outros e muito - possivelmente - vão fazer pior. Ou então (minha alternativa final) nós - e o momento que se acelera rapidamente vamos ficar, bibliograficamente, um século ou ainda mais para trás.' (CLAPP 1956, apud TAUBER, 1957, p. 58).

Uma pequena digressão: O termo bibliografia cai de moda, agora fala-se base de dados. Com isso, perdem-se alguns critérios para levantamentos bibliográficos sistemáticos, correntes ou não. Mas não se podem dissociar os dois conceitos: bibliografia e bases de dados; ambos organizam informação; de alguma forma continuam associados em especial por algumas técnicas e procedimentos comuns. Por outro lado, no entanto, com aquele ou com este nome, a preocupação de Clapp permanece: a introdução da computação nas atividades de informação, atualmente, mais do que nunca, requer a participação de profissionais da informação em especial no trato das questões semânticas e tudo o que isso acarreta.

Nos Estados Unidos, bibliotecários especializados atuaram desde o início em tais atividades. Em conjunto com outros profissionais como engenheiros, químicos, especialistas em computação participaram das reuniões do Geórgia Tech em que discutiram a nova área de conhecimento, nomeada e definida no início dos anos 60 como Ciência da Informação, área que continua buscando soluções para problemas já enfrentados pelas bibliotecas técnicas, de laboratórios de pesquisa e assemelhados, desde o século XIX, contando então com apoio das tecnologias da informação.

Este campo trouxe alguns atritos com a comunidade de bibliotecários tanto no Reino Unido, como na Alemanha e, provavelmente, em outros países. Nos Estados Unidos, a união das diferentes atividades profissionais parece ter sido fácil e rápida. American Documentation Institute passa a se chamar American Society for Information Science. Na França, enquanto a formação de bibliotecários ficou a cargo da École des Chartes, os documentalistas se reuniram na Union Française des Oganismes de Documentation, marcando uma separação entre os dois campos de atuação. Na Alemanha, bibliotecários 
e documentalistas têm uma longa história de desentendimentos (SAMULOWITZ; OCKENFELD, 2003).

No Brasil, os bibliotecários tiveram grande presença nas atividades de documentação, a partir da criação do Instituto Brasileiro de Biblioteconomia e Documentação (1954), mas a introdução da computação no tratamento da informação criou um certo impacto entre os bibliotecários que perceberam, no entanto, que o tratamento automático do assunto dos documentos não produzira resultados tão satisfatórios naquele momento. Nos Estados Unidos, a Ciência da Informação e a Biblioteconomia se fundiram na nova área agora indicada pela sigla LIS (Library and Information Science) e no Brasil as Escolas de Biblioteconomia têm aparentemente atuado nesta direção - mas não tanto.

Um dos aspectos mais significativos para a união das duas áreas num novo campo de conhecimento foi a Organização do Conhecimento. Experiências anteriores na organização dos assuntos/do conhecimento se mostraram ainda válidas mesmo em ambiente digital, embora em outro nível, ou mesmo no surgimento de novos produtos informacionais. Neste contexto, a classificação tem estado sempre presente, seja na construção de taxonomias e ontologias, seja na construção de sítios ou de qualquer outro serviço de organização de objetos digitais. ${ }^{13}$

A Web Semântica é o marco que vai atender as expectativas e esperanças dos profissionais de informação, desde sempre. (Lembremos Vannevar Bush com o Memex). Finalmente, a Semântica no horizonte próximo, e os metadados, e as ontologias. A organização dos recursos de informação torna-se possível na tela do computador, trazendo meios de navegação/acesso, sem descurar dos dispositivos de recuperação, presentes em diversos produtos; serviços e saberes novos como a construção de portais e arquitetura de informação são os novos desafios da organização da

13 Atualmente as atividades de tratamento e recuperação da informação despertam grande interesse, mas a busca pelo conhecimento da História da área, em nosso País, tem levado a estudos mostrando o entrelaçamento da tecnologia com aquelas atividades. Cf o texto de (Ortega 2004; Siqueira, 2010).

Inf. Inf., Londrina, v. 22, n. 2, p. 33 - 66, maio/ago., 2017. 
informação. Releva, igualmente, a retomada dos estudos visando recuperação inteligente, com as propostas dos ontologistas.

No que tange à organização do conhecimento, as ontologias para representá-lo apóiam-se em termos e relações, ambos aspectos familiares aos profissionais de informação, embora com novos ingredientes.

\section{MARCOS TEÓRICOS}

Cada marco teórico se caracteriza pela contribuição de princípios, critérios, métodos provocados pelos novos produtos, serviços, procedimentos, técnicas, usuários e entrada de novos parceiros.

Biblioteconomia/Ciência da Informação é uma área de pesquisa relativamente nova. As contribuições teóricas têm início a partir da segunda metade do século XIX, ainda de modo tímido, com os primeiros classificacionistas e suas reflexões sobre cada esquema por eles desenvolvido. No século XX surgem os primeiros livros sobre Teoria da Classificação aplicada à organização de livros e abordagens teóricas. Mas a atividade bibliográfica já registrava reflexões e propostas a respeito da ordenação do conhecimento registrada no mundo dos livros.

No universo da organização do conhecimento fora do âmbito dos esquemas de classificação não se pode esquecer Kaiser (1911) que foi o primeiro a desenvolver um modelo para a indexação, com as categorias Coisa, Processo e Lugar.

A ordenação é básica na Organização do Conhecimento e podemos entender tal atividade como tendo a classificação como um ingrediente central. Nos tempos atuais, dois momentos são significativos na trajetória da Teoria da classificação na Organização do Conhecimento:

- esquemas influenciados por propostas de classificação das ciências por filósofos e cientistas;

- esquemas facetados. 
A divisão acima a que nos referimos, leva em consideração os critérios de recorte do conhecimento nos esquemas de classificação.

A área de conhecimento que mais impacto provocou inicialmente foram as classificações bibliotecárias; princípios teóricos vários embasaram os vários esquemas de classificação bibliotecária destacando-se: Dewey/Harris (1876) -; Cutter (Expansive, 1891-1893), Brown (Subject classification,1906) - QuinnBrown Classification, Adjustable classification -, Bliss (Bibliographic classification, 1933).

A necessidade de desenvolver esquemas reunindo todos os campos do saber levou os classificacionistas a buscar nos filósofos/cientistas apoio para suas realizações.

Francis Bacon é uma referência ainda no século XIX. Sua proposta de organização da ciência foi adaptada por William T. Harris eminente estudioso e educador norte-americano e um Hegeliano bastante conhecido em seu tempo (GRAZIANO, 1959; OLSON 2011), cujo esquema elaborado por sua pequena biblioteca particular influenciou Dewey. (LEIDECKER 1946).

Ainda no século XIX inicia-se um movimento de classificação das ciências que não parte das disciplinas científicas tradicionais, 'em resposta ao fenómeno da constituição de novos ramos fundamentais do conhecimento científico' e 'a classificação da ciência é então atividade filosófica autónoma' (POMBO, 1998). Neste contexto, para o que nos interessa aqui, estão as contribuições de Comte e Spencer que teriam influenciado os sistemas de Brown e Bliss. Igualmente, a filosofia evolucionária exerceu influência em seus esquemas. (BLISS, 1910; BLISS, 1929; BROWN, 1906). E, mais tarde, a teoria dos níveis integrativos que não está ligada a uma escola filosófica, foi alvo do estudo de vários filósofos.

No século $X X$, dois filósofos sistematizaram as leis dos níveis: Feiblemann na Inglaterra, influenciador da proposta do CRG (Classification Research Group) e Nicolai Hartmann, na Alemanha, influenciador da proposta utilizada por Dahlberg no ICC (Information Coding Classification). (GNOLI, 2004; DAHLBERG, 2008) 
No âmbito dos níveis integrativos ressalta-se a contribuição de Austin (1969), que desenvolveu diversos princípios que 'poderiam ser usados para aumentar a teoria do nível integrativo'. (WILSON 1972); mas ele interrompe os estudos quando vai atuar na British National Bibliography. Wilson resume as duas conclusões principais a respeito da aplicação da teoria dos níveis integrativos à construção de esquemas de classificação bibliográfica: Em primeiro lugar, a) níveis integrativos produzem uma estrutura ramificada e não uma seqüência única; b) a implicação disto é que a teoria não pode oferecer uma base para uma seqüência única inequívoca de classes. Em segundo lugar, a teoria não ajudou a determinar uma ordem para idéias abstratas (mentefatos) ou artefatos. Mas a teoria continua sendo objeto de pesquisa.

A próxima iniciativa ocorre com Dahlberg e sua Information Coding Classification (ICC) (DAHLBERG 2008), e atualmente com Gnoli (2004) e o projeto ILC, este último retomando princípios desenvolvidos por Austin. ICC foi utilizada por Dahlberg na bibliografia corrente sobre Classificação incluída como uma seção do periódico International Classification. Parece, contudo, que ainda não tem um uso amplo. A iniciativa de Gnoli ainda é recente, vamos aguardar os desdobramentos. Gnoli argumenta que uma classificação segundo os princípios da teoria dos níveis integrativos, ao prever um único código é relevante para a recuperação de objetos digitais, pois não importa em qual contexto esteja referido, isso potencializa sua recuperação. $O$ código único causou estranheza quando Brown propôs tal princípio para organização física dos livros, mas eram outros tempos e outro objetivo, outra tecnologia.

Embora os classificacionistas acima citados sejam relevantes para o desenvolvimento da Ciência da Informação enquanto área científica, suas contribuições ficaram restritas, exceto a Classificação Decimal de Dewey que se popularizou pelo menos no mundo ocidental, graças, principalmente, ao tipo de notação adotado. Talvez o amadurecimento da Ciência da Informação explique os inúmeros estudos a respeito daquelas contribuições. E podem oferecer subsídios para algum marco teórico no que respeita a construção de esquemas de classificação bibliotecária. 
Vimos que, historicamente, o CRG foi um marco. E defendemos que este Grupo tem seu lugar proeminente também como Marco Teórico na Ciência a Informação. Pode-se perguntar agora: e Ranganathan?

Em 1933 Ranganathan publica sua Colon Classification, que adota um princípio castegorial para recortar cada classe de seu esquema. Trata-se de suas conhecidas Categorias Fundamentais (Personalidade, Matéria, Energia, Espaço e Tempo) que reúnem as respectivas Facetas ou aspectos específicos de cada área do conhecimento. Seu uso ficou restrito à India e, naquele momento, sua contribuição não causou impacto.

Constituído de pesquisadores envolvidos com a construção de ferramentas para várias empresas de caráter científico e tecnológico, os membros do CRG reuniam-se para trocar experiências, cujas discussões estão em seus Boletins publicados no periódico Journal of Documentation onde podemos acompanhar as questões com que se defrontavam. A principal contribuição do Grupo foi trazer os princípios da Classificação Facetada de Ranganathan não apenas para o desenvolvimento de esquemas especializados como para o novo ambiente da organização da informação em bases de dados. Assim, apesar da obra de Ranganathan relativa ao método de Faceta remontar à década de 20, e seu esquema limitado à Índia, foi o CRG que retomou e avançou o método. ]

A ruptura da Colon Classification estava no modelo de organização no interior de cada área principal de seu esquema. Alí a subdivisão não se daria por subdivisões temáticas, mas por categorias, cujo modelo seria comum para todas as áreas. O exemplo emblemático de tal mudança é o Thesaurofacet de Jean Aitchison (1970) que serviu de índice para o respectivo esquema de classificação. Ao adotá-lo no desenvolvimento de repertórios bibliográficos bem 
como na construção dos inúmeros tesauros desenvolvidos por seus membros, o CRG mostrou a potência do método tornando-o popular. ${ }^{14}$

Desde então, esse método tem-se mostrado adequado igualmente para a organização de recursos em meio digital em praticamente todos os tipos de produtos e serviços. Vale ressaltar a contribuição de Vickery com 0 'detalhamento' das Categorias Fundamentais, tornando o modelo mais palatável (VICKERY, 1966). Os princípios e cânones de Ranganathan oferecem ainda possibilidades de construção de taxonomias. Nos Prolegomena (RANGANATHAN 1967) encontram-se todos os elementos para organizar não apenas taxonomias consistentes bem como intrerface de navegação.

Se fizermos levantamentos na internet a respeito de métodos e princípios para orgnização da informação e do conhecimento, veremos que o Método de Faceta é, por assim dizer, uma quase unanimidade, sempre que se pensa em organização semântica para apoiar os diversos produtos e serviços na Web. Impossível listar aqui os resultados de uma busca sobre o tema.

Mas um aspecto deixou de ser abordado pelo CRG: as unidades verbais dos tesauros.

O uso de termos da linguagem natural ao lado dos sistemas facetados traz um novo personagem, melhor, uma personagem, como marco teórico: Dahlberg e sua Teoria do Conceito.

A Terminologia tem sua origem na necessidade de uma nomenclatura de produtos e serviços para facilitar trocas internacionais (WÜSTER, 1981). Várias Escolas de Terminologia surgem daí. Uma das questões centrais, é o termo, a outra, arranjo sistemático. Para o que nos interessa, agora, são os fundamentos teóricos para apoiar padrões terminológicos de apoio ao desenvolvimento de produtos e serviços especializados para serem processados por computadores. O que a Teoria do Conceito nos fornece:

\footnotetext{
14 Sugere-se consultar os boletins do CRG para acompanhar as discussões teórias e práticas de seus membros, bem como a literatura produzida por alguns de seus eminentes membros como Brian Vickery, Douglas Foskett, Jack Mills, Derek Austin, Farradane, Barbara Kyle.
}

Inf. Inf., Londrina, v. 22, n. 2, p. 33 - 66, maio/ago., 2017. 
elementos para identificar um conceito como resultado da análise do referente, o que nos leva à definição. ${ }^{15}$ Esta, segundo Dahlberg, tem natureza estruturante, produzindo hierarquias (taxonomias) e contribuindo igualmente para as ontologias.

Um aspecto positivo e útil na produção da terminologia é que a abordagem de Dahlberg é onomasiológica. Partindo das proposições verdadeiras sobre um referente - obtido no discurso em um dado contexto Dahlberg fornece elementos para sua identificação e descrição, propiciando estruturação consistente na representação de um domínio, de uma técnica, ou de qualquer atividade. Adotando o princípio do genus proximum et differentia specifica de Aristóteles, a definição mostra seu poder estruturante, que se ajusta ao método de Faceta (ambos trabalham com a unidade de conhecimento). O arranjo sistemáticao necessário à produção de uma dada terminologia se apoia nas categorias ampliadas do CRG (VICKERY, 1966) oriundas de Ranganathan, que Ihe dão suporte para tal arranjo. Por tudo isso, Dahlberg se constitui no marco teórico mais recente, cuja Teoria 'costura' princípios de classificação (claramente influenciada por Ranganathan neste aspecto) (DAHLBERG, 1978 a) e de terminologia sistemática. Ambos se fixaram na unidade semântica, daí o sucesso no arranjo e combinação de conceitos seja para recuperação seja para navegação.

\subsection{Teoria da Classificação: primeiros textos}

Marcos teóricos importantes são, ainda, os livros que abordam questões teóricas típicas da classificação de livros, e que lançam as bases para o desenvolvimento do campo. Relevam os livros de Ernest Cushing Richardson e Berwick Sayers.

\footnotetext{
15 As questões lexicais presentes na elaboração de tesauros já estão resolvidas, de certa forma, pelos desenvolvedores de instrumentos semânticos
} 
Considerado como o principal livro de teoria da Classificação, Classification, Theoretical [!] and practical de Richardson tem sua primeira edição em 1901 com atualização em 1912. Contém duas palestras - A Ordem das Ciências e A Classificação de livros. Para ele 'a classificação de livros nas bibliotecas deveria refletir o universo de conhecimento e que uma enumeração ordenada das disciplinas principais - ou, na linguagem do dia, as ciências deveria fornecer a estrutura das classes principais, da qual deveriam proceder as subdivisões' (DOUSA, 2015); 'em outras palavras, a classificação bibliotecária deveria se basear, mutatis mutandis, na ordem das ciências'. Essas idéias encontram-se também em Cutter (1879) e Sayers (1918). Seu livro parece 'ter sido o primeiro trabalho no emergente campo da biblioteconomia inteiramente voltado para a formulação de uma teoria sistemática da classificação e assim veio a exercer uma influência considerável nos proponentes estudiosos da teoria da organização do conhecimento como Sayers e Bliss' (DOUSA, 2010). Dois terços restantes de seu livro contêm, em um Apêndice, Sistemas de classificação elaborados por filósofos e eruditos, e sistemas práticos, dedicados à biblioteca e à bibliografia. À guisa de curiosidade, ele registra mais de 150 sistemas teóricos (desde Platão) e mais de 170 sistemas práticos (desde Calímaco, na Alexandria, até Bliss).

Em 1918, Sayers publica An Introduction to Library classification; o conteúdo é dividido em duas partes: Teórica, História e prática. A primeira contém noções básicas como os princípios de lógica para a construção da classificação, noção de classes, princípios de divisão. Já é bastante didático, e é também um clássico. Sayers foi professor e, como tal, influenciou gerações posteriores de classificacionistas, dentre eles Ranganathan e alguns membros do futuro CRG.

A terceira contribuição do período deve-se a Bliss com seus dois livros: The Organization of Knowledge and the System of the Sciences (1929) e The Organization of Knowledge in Libraries (1933). Antes de construir seu próprio esquema, Bliss analisa os mais populares em uso registrando seus comentários e críticas no livro The Organization of knowledge in libraries 
(1939), mostrando as deficiências das classificações bibliográficas, face ao movimento de classificação da ciência.

\section{CONSIDERAÇÕES FINAIS: SOBRE A CLASSIFICAÇÃO COMO CAMPO CIENTÍFICO}

A Classificação de livros, e todo o arcabouço teórico que daí surge, nasce na Biblioteconomia, mas hoje é uma área de conhecimento independente, quando o foco da ação se desloca da organização física para a organização dos conteúdos, deslocamento que deu origem à Ciência da Informação. A existência de sociedades científicas, encontros, pesquisas comprovam tal afirmativa.

Hoje, a classificação em seus aspectos teórico e prático é fundamental para a organização do conhecimento como também para a gestão do conhecimento nas organizações; para produtos e serviços como portais, intranets, arquitetura de informação;para a criação de instrumentos semânticos; e até mesmo criação de metadados, na maioria das vezes associados a facetas, os quaiss têm igualmente, papel na organização do conhecimento.

Para resumir, na primeira metade deste século estamos presenciando o surgimento de muitas outras tecnologias e serviços, mas as questões levantadas por Langlois são válidas e talvez estejam agravadas nos tempos atuais. A Bibliografia é "a mais antiga manifestação da documentação, e parece tão velha quanto a Biblioteconomia, e em seus primórdios ambas eram indistinguíveis umas das outras" (SHERA; EGAN, 1961). O panorama pode mudar, conforme novas evidências surjam. Importante é ressaltar que organizar os livros - tomados aqui em seu sentido mais amplo - e seu conteúdo, é uma antiga necessidade do homem e sistematizá-los atende à primeira Lei de Ranganathan: Livros são para usar.

Por fim, poderíamos afirmar que a classificação - em seu sentido mais amplo - é imprescindível às atividades de registro de recuperação de comunicação de recursos. Existe contribuição teórica para explorar as TI com 
criatividade para os diversos serviços e produtos requeridos pela sociedade. E não podemos nos esquecer que a Classificação é a espinha dorsal para a solução das questões semânticas, com larga tradição na Ciência da Informação.

E também para os demais desafios da Web Semântica, indaguemos sempre: O que nos cabe neste latifúndio?

\section{REFERÊNCIAS}

AITCHISON. J. The thesaurofacet: a multipurpose retrieval language tool. Journal of Documentation, v. 26, n.3, 1970, p. 187-203.

AUSTIN, D. Prospects for a new general classification. Journal of Librarianship and Information Science, v. 1, n. 3, July, 1969, p. 149-169.

BARRETO, Aldo. A Condição da informação. São Paulo em Perspectiva, São Paulo, SP. Fundação SEADE-SP, v. 16, n. 3, 2002, p. 67-74.

BARRETO, Aldo. A História da ciência da informação. DataGramaZero, v. 09, 2008, p. 1-15.

BLISS, H. E. A modern classification for libraries. Library Journal, v. 35, Aug. 1910, p. 351-358.

BLISS, H. E. The Organization of Knowledge and the System of the Sciences. New York: Henry Holt, 1929. Cap XVIII.

BLISS, Henry Evelyn. The Organization of knowledge in libraries and the subject approach to books. 2 ed., rev, and partly rewritten. New York: Wilson, 1939.

BROUGHTON, Vanda. Brian Vickery and the Classification Research Group: the legacy of aceted classification. 2011. Disponível em: $<$ www.iskouk.org/conf2011>.

BROWN, James D. Subject classification, with tables, indexes, etc, for the subdivision of subjects. London: Library supply, 1906. 
COMPAYRÉ, Gabriel. Talleyrand et la réforme de léducation sous la Révolution française. Encyclopédie de l'Agora, 2012. Disponível em:

$<$ http://agora.qc.ca/documents/revolution francaise--

talleyrand et la reforme de leducation sous la revolution francaise par ga briel compayre>.

CUTTER, C. A. Classification on the shelves: with some accounts of the new schema prepared for the Boston Atheneum. Library Journal, v. 4, 1879, p. 234-243.

DAHLBERG, Ingetraut. The Information Coding Classification (ICC): a modern, theory-based fully-faceted, universal system of knowledge fields. Axiomathes, v. 18,2008, p. $161-176$.

DAHLBERG, Ingetraut. Ontical Structures and Universal Classification. Bangalore: Sarada Ranganathan Endowment for Library Sciences Series II, Sarada Ranganathan Lectures II. 1978a

DOUSA, T. M. Categories in Charles A. Cutter's Systems of subject cataloging and bibliographical classification. 2015. Disponível em:<http://www.iskocus.org/NASKO2015proceedings/Dousa.pdf>.

DOUSA, T. M. The simple and the complex in E. C. Richardson's theory of classification: observations on an early $\mathrm{KO}$ model of the relationship between ontology and epistemology. In.: GNOLI, C. \& MAZZOCCHI, F. (eds) Paradigms and conceptual systems for knowledge organisation. Proceedings of the tenth International ISKO Conference, Rome, 23-26 Feb.. Würzburg, Ergon, 2010. p.15-23

GNOLI, C.. Integrative Levels Classification. 2004. Disponível em: <http://www.iskoi.org/ilc $>$.

GRAZIANO, E. E.. Hegel's philosophy as basis for the Dewey Classification schedule. Libri. v. 9, n. 1/4, 1959, p. 45-52.

KAISER, J. Systematic indexing. London: [s.n.], 1911.

KENT, Allen. Information analysis and retrieval. New York: Becker and Hayes, 1971. p. 6-7

LA RÉVOLUTION française et l'émancipation par l'éducation: Talleyrand, Condorcet, Danton, Lepeletier et Robespierre. Jacques Serieys Sélection 23. Disponível em: <http://www.gauchemip.org/spip.php?article908>. Acesso em: 11 de abril de 2014.

LEIDECKER, K. F. Yankee teacher: The life of William Torrey Harris. New York: The Philosophical Library, 1946. 
LÉTOUBLON, F.; SGARD, Jean Le. Catalogue comme representation de la bibliothèque. Disponível em: $<$ www.voxpoetica.com/sflgc/biblio/bibliafin/letoublonsgard.html>. Acesso em: 1 de julho de 2014.

MALCLĖS, L-N. La Bibliographie. Paris: Presses Universitaires de France, 1956.

MANGUEL, A. Uma história da leitura. Rio de Janeiro: Companhia das Letras, 1997.

METCALF, J.. Subject classifying and indexing of libraries and literature. New York: Scarecrow Press, 1959.

MUDDIMAN, Dave. A new history of ASLIB, 1824-1950. Journal of Documentation, v. 61, n. 3, 2005, p. 402-428.

NAUDÉ, Gabriel. Advis pour dresser une bibliotheque. 1627. Disponível em: $<$ http://www.enssib.fr/bibliotheque-numerique/documents/48749-advis-pourdresser-une-bibliotheque-par-gabriel-naude.pdf $>$

NELLES, Paul. Reading and memory in the Universal Library: Conrad Gessner abd the Renaissance book. In: BECKER, Donald; WILLIAMS, Grant. Ars riminiscendi: Mind and memory in Renaissance culture. Toronto: Centre for Reformation and Renaissance Studies, 2009. p. 147-169.

OLSON, Hope. A potência do não percebido: Hegel, Dewey e seu lugar na corrente principal do pensamento classificatório. InCID Revista de Ciência da Informação e da Documentação, v. 2, n.1, jan/jun 2011, p. 3-15.

ORTEGA, Cristina Dotta. Relações históricas entre Biblioteconomia, Documentação e Ciência da Informação. DataGramaZero - Revista de Ciência da Informação, v.5, n.5, out. 2004.

POMBO, Olga. Da classificação dos seres à classificação dos saberes. Revista da Biblioiteca Nacional de Lisboa, n. 2, 1998.

RANGANATHAN, S. R. Prolegomena to Library classification. Bombay: Asia Publishing House, 1967.

RICHARDSON, E. C. Classification, Theoretical [!] and practical. New York: Scribner's sons, 1912.

SAMULOWITZ, H.; OCKENFELD, M. Bibliothek und Dokumentation: eine unendliche Geschichte. Information, v. 54, 2003, p. 353-462. 
SAYERS. W. C. Berwick. An Introduction to Library Classification: With Readings, Questions and Examination Papers. London: Grafton, 1918.

SCHULTE-ALBERT, Hans G. Gottfried Wilhelm Leibniz and Library Classification. The Journal of Library History, v. 6, n. 2, Apr. 1971, p. 133-15.

SHERA, J.H. EGAN, M.E. Exame do estado atual da biblioteconomia e documentação. In.: BRADFORD, S.C. Documentação. Rio de Janeiro: Fundo de cultura, 1961.

SPITERI, Louise. The Classification Research Group and the theory of integrative levels. The Katherine Sharp Review. 1995. Disponível em:<http://www.lis.uiuc.edu/review/summer1995/spiteri.pdf>.

TAUBER, Maurice F. Classification, Cataloging and Indexing systems. In: SHERA, J. (Org.). Information systems in documentation. New York: Interscience, 1957. V. II, p. 39-65.

VICKERY, Brian C. Faceted classification schemes. New Brunswick: Graduate School of Library Science, Rutgers University, 1966.

WILSON, T. D. The work of the British Classification Research Group. In: WELLISCH, Hans (Org.). Information retrieval in the seventies: new directions. Westport: Greenwood, 1972. p. 62-71.

WÜSTER, Eugen. L'étude scientifique générale de la terminologie, zone frontalière entre la Linguistique, la Logique, l'Ontologie, I'Informatique et les Sciences des Choses. In: RONDEAU, G.; FELBER, F. (Org.). Textes choisis de terminologie: I: fondéments théoriques de la terminologie. Québec: GIRSTERM, 198. p. 57-114.

Title

Historical and theoretical landmarks of the knowledge organization

\begin{abstract}
Introduction: The study recognizes a set of historical and theoretical demarcations in Knowledge Organization, which cross Antiquity, Middle Ages, Modernity and contemporaneity. The technical and theoretical elements are discussed, from writing to the semantic web, as complementary instances in the development of techniques and theories of knowledge organization and representation. Objectives: The paper investigate two aspects relevant in the emergence and development of Library and Information Science: the technologies and the reflections that mark theoretical approaches. Methodology: The study proposal is a historical review, based on bibliographical sources, on the construction of ideas and artifacts in Knowledge Organization. Results: Each resulting information product brought, over time, reflection
\end{abstract}

Inf. Inf., Londrina, v. 22, n. 2, p. 33 - 66, maio/ago., 2017. 
on the various actions. Among the relevant theoretical frameworks to highlight are Kaiser with its indexing model, Ranganathan's Classification and the Research Group Classification, Dahlberg's Concept Theory, which complements it with principles of definition, contributing to the development of taxonomies and ontologies. Conclusions: The study demonstrates the objective relationship between the technical transformations and the theoretical development of the Knowledge Organization, allowing the contextual identification of the theoretical framework of the domain.

Keywords: Knowledge Organization. Knowledge Organization History. Knowledge organization and representation technologies. Knowledge Organization Theory.

\section{Título}

Marcos históricos y teóricos de la organización del conocimiento

\section{Resumen}

Introducción: El estudio reconoce un conjunto de demarcaciones históricas y teóricas en Organización del Conocimiento, que atravesan la Antigüedad, la Edad Media, la Modernidad y la contemporaneidad. Los elementos técnicos y los elementos teóricos son discutidos, de la escritura a la web semántica, como instancias complemanteres en el desarrollo de las técnicas y de las teorías de organización y representación del conocimiento. Objetivos: Abordar los aspectos que consideramos relevantes en el surgimiento y desarrollo de la Biblioteconomía / Ciencia de la Información: las tecnologías y las reflexiones que marcan enfoques teóricos. Metodología: La propuesta del estudio es una revisión histórica, a partir de fuentes bibliográficas, sobre la construcción de las ideas y de los artefactos en Organización del Conocimiento. Resultados: Cada producto de información resultante trae, con el tiempo, reflexión sobre los diversos hechos. Entre los marcos teóricos relevantes a destacar están Kaiser con su modelo de indexación, la Clasificación Facetada de Ranganathan vía Classification Research Group, la Teoría del Concepto de Dahlberg, que la complementa con principios de definición, contribuyendo al desarrollo de taxonomías y ontologías. Conclusiones: el estudio demuestra la relación objetiva entre las transformaciones técnicas y el desarrollo teórico de la Organización del Conocimiento, permitiendo identificar, contextualmente, los grandes marcos teóricos del dominio.

Palabras clave: Organización del Conocimiento. Historia de la Organización del Conocimiento. Tecnologías de organización y representación del conocimiento. Teoría de la Organización del Conocimiento.

Recebido: 10.03 .2017

Aceito: 25.08 .2017 